\title{
A VALORIZAÇÃO DA IDENTIDADE TERRITORIAL E INOVAÇÃO SUSTENTÁVEL: ESTRATÉGIAS DE COMPETITIVIDADE, APLICADOS EM POLOS MOVELEIROS PERNAMBUCANOS EMERGENTES
}

\section{THE VALORIZATION OF TERRITORIAL IDENTITY AND SUSTAINABLE INNOVATION: COMPETITIVENESS STRATEGIES, APPLIED IN EMERGING PERNAMBUCAN MOVING POLES.}

\section{Paulo Roberto Silva, M.Sc. (UFPE)}

Amilton Jose Vieira Arruda, Dr. (UFPE)

\section{Palavras-chave:}

Arranjos Produtivos; Setor Moveleiro; Design e Território.

Key Words:

Productive arrangements; furniture industry; Design and territory.

\section{RESUMO}

Este artigo se refere a uma revisão teórica sobre a valorização do Design, território e sustentabilidade, que são ferramentas fundamentais na formação de Arranjos Produtivos e Inovadores Locais, sendo delimitados num território (espaço geográfico) impregnado de aspectos simbólicos e identidades culturais. Quando se fala em design sustentável no setor moveleiro, deve-se pensar na cadeia produtiva como um todo, desde a origem da matéria prima, insumos e materiais, passando pelo projeto, processo, distribuição, uso e descarte dos produtos, que é uma visão ampliada do design, contribuindo para o desenvolvimento sustentável dos polos moveleiros estudados neste projeto de extensão, sedimentando a base para formação de Arranjos Produtivos Inovadores Locais, baseados nesta valorização do território.

\section{ABSTRACT}

This article refers to a theoretical review on the development of Design, territory and sustainability, which are fundamental tools in the formation of Clusters and innovative locations, being enclosed in a territory (geographic area) steeped in symbolic aspects and cultural identities. When it comes to sustainable design in the furniture sector, one must think in the production chain as a whole, since the origin of the raw material, supplies and materials, project, process, distribution, use and disposal of products, which is an enlarged view of the design, contributing to the sustainable development of polo furniture makers in this extension project studied, settling the basis for formation of an Innovative Local productive arrangements based on this valuation of the territory. 


\section{INTRODUÇÃO}

A globalização mundial trouxe uma transformação intensa nos mercados, no desenvolvimento da tecnologia, impactando a competitividade das organizações. Diante da situação atual, o design vem sendo reconhecido como uma ferramenta estratégica para a valorização e a promoção do território, preservando a identidade e cultura regional. Para (Krucken, 2006), a valorização de recursos e produtos locais tem sido um tema muito rico e complexo, pois produtos concebidos envolvem simultaneamente dimensões físicas e cognitivas. Diante disto se faz necessário, ainda segundo a pesquisadora, perceber as qualidades do contexto local (o território) e a forma como cada produto é criado, depois fabricado, para então compreender as relações que se formam em torno da produção e do consumo dos produtos.

Tendo como objetivo geral este estudo como uma atividade de extensão em andamento, procura analisar os referenciais teóricos sobre a temática, exemplos, práticas exitosas, para a partir desta fundamentação e pesquisa, sedimentar pilares para uma intervenção futura na formação de Arranjos Produtivos Inovadores Locais nos polos moveleiros pernambucanos, que segundo o SEBRAE quando se fala em um Arranjo Produtivo Local, deve-se considerar, em primeiro lugar, a existência de uma aglomeração de um número significativo de empresas que atuam em torno de uma atividade produtiva principal.

Finalmente, a partir da fundamentação e referenciais teóricos de pesquisadores, ter subsídios de como se deve implementar o design na valorização do território nos polos moveleiros, com exemplos em dois emergentes, que segundo classificação do SEBRAE são incipientes, ainda na primeira fase de formação.

\section{FUNDAMENTAÇÃO TEÓRICA E RESULTADOS PRÁTICOS.}

\subsection{Valorização da identidade territorial}

Um fator determinante de diferencial competitivo para as empresas é a condição dos produtos e serviços ligados ao território e à sociedade nos quais surgiram, que reflete no conceito de terroir. Para (Krucken, 2009, p:31), o conceito de terroir abrange o produto, o território e a sociedade que o produz, neste espaço geográfico existem relações sociais, econômicas, culturais, ecológicas, com diversos níveis de complexidade.

Terroir é um termo de origem francesa (lê-se terroar), provém do latim popular (terratorium) alterado no galo-romano (territorium; territoire). Usa-se também a expressão produtos de terroir para designar um produto próprio de uma área limitada.

O Terroir, na ampliação do conceito desenvolvido por geógrafos franceses, é um conjunto de terras sob a ação de uma coletividade social congregada por relações familiares e culturais e por tradições de defesa comum e de solidariedade da exploração de seus produtos.

Ainda segundo (Krucken, 2009, p:49), a abordagem do design estratégico aplicado num determinado território, tem como objetivos beneficiar simultaneamente produtores e consumidores, valorizando conjuntamente o capital territorial e o social, sempre buscando sustentabilidade a longo prazo. Isto reflete numa mudança de paradigma, numa sinergia entre os atores, produtores e empresas, que se fortalecem e se complementam sua capacidade de competição no mercado local e global.

Alguns exemplos práticos. Em (KRUCKEN, 2009 apud FORTIS, 2007): A habilidade das pequenas e médias empresas italianas de associarem-se em arranjos produtivos é uma das bases para o sucesso dos produtos Made in Italy, que representam um ponto forte do sistema industrial italiano: "Os consumidores buscam emoções que Ihes permitam compartilhar um estilo de vida". A notável associação das marcas e dos produtos italianos à sua origem reflete essa valorização do território, dos modos de fazer e de consumir produtos.

No Brasil já se observa uma crescente valorização de territórios a partir de produtos, onde a união de atores promove inovações conjuntas que impulsionam o investimento regional. Esse é o caso dos famosos Doces de Pelotas, da cachaça de Luís Alves e de Salinas, do Café do Cerrado Mineiro, dos vinhos do Vale dos Vinhedos e do queijo do Serro em Minas Gerais, além de diversos outros produtos que trazem em si características dos territórios de origem e das comunidades que os produziram. Todos estes exemplos convergem para o entendimento de que os lugares também podem ser pensados com "produtos" que podem ser consumidos de diversas maneiras e por diferentes públicos.

\subsection{Os Arranjos Produtivos e Inovativos Locais}

A competitividade das empresas no mercado globalizado está muito ligada à sua capacidade de atuação cooperativamente em Arranjos Produtivos Locais. As discussões recentes têm focalizado a forma dos Arranjos Produtivos e Inovadores Locais (APIL's) como pequenos fornecedores estabelecidos em torno de uma grande empresa ou por cooperação de micro e pequenas empresas (MPE's) que interagem entre si e com outros 
agentes espacialmente próximos, conforme (Lastres et al., 1999). Outras dimensões de "sistemas inovadores" também procuram destacar a importância dos processos de construção de capacidades inovadores, o papel das instituições no desenvolvimento econômico, os efeitos sinérgicos de esforços cooperativos ao lado da pressão competitiva e a necessidade de políticas públicas para a evolução de "localidades produtivas".

É recente, a partir das últimas décadas do século $\mathrm{XX}$, a intensificação da promoção de aglomerações produtivas e inovadores locais. Estas aglomerações passam a ser principais fatores de alavancagem do desenvolvimento de uma nação.

Segundo Porter, "Um aglomerado é um agrupamento geograficamente concentrado de empresas inter-relacionadas e instituições correlatas numa determinada área, vinculadas por elementos comuns e complementares. $\mathrm{O}$ escopo geográfico varia de uma única cidade ou estado para todo um país ou mesmo uma rede de países vizinhos. Os aglomerados assumem diversas formas, dependendo de sua profundidade e sofisticação, mas a maioria inclui empresas produtos ou serviços finais, fornecedores de in sumos especializados, componentes, equipamentos e serviços, instituições financeiras e empresas em setores correlatos. Os aglomerados geralmente também incluem empresas em setores a jusante (ou seja, distribuidores ou clientes), fabricantes de produtos complementares, fornecedores de infraestrutura especializada, instituições governamentais e outras, dedicadas ao treinamento." (Porter, 1989, p:211).

Para o Serviço Brasileiro de Apoio as Empresas Sebrae os arranjos produtivos são aglomerações de empresas localizadas em um mesmo território, que apresentam especialização produtiva e mantêm algum vínculo de articulação, interação, cooperação e aprendizagem entre si e com outros atores locais tais como governo (municipal, estadual e federal), associações empresariais, além de instituições de crédito, ensino e pesquisa. Ainda segundo o SEBRAE, um Arranjo Produtivo Local é caracterizado pela existência da aglomeração de um número significativo de empresas que atuam em torno de uma atividade produtiva principal.

Quadro 1 - Grau de estágio do APL.

\begin{tabular}{|c|c|c|}
\hline Estágio & Características & Determinantes \\
\hline Arranjos incipientes & $\begin{array}{l}\text { Não tem articulação e carência de lideran- } \\
\text { ças legitimadas; } \\
\text { Não possuem integração entre empresas e } \\
\text { poder público; } \\
\text { Seu mercado ainda é o local ou microrre- } \\
\text { gional, não apresentando competitividade } \\
\text { para tentativas mais arrojadas. }\end{array}$ & $\begin{array}{l}\text { Baixo desempenho empresarial; } \\
\text { Foco individual; Isolamento entre } \\
\text { empresas; } \\
\text { Ausência de apoio/presença de entidade } \\
\text { de classe; Mercado local; } \\
\text { Base produtiva mais simples. }\end{array}$ \\
\hline $\begin{array}{l}\text { Arranjos em } \\
\text { desenvolvimento }\end{array}$ & $\begin{array}{l}\text { Suas lideranças empresariais são mais legiti- } \\
\text { madas e capacitadas, atuando em entidades } \\
\text { de classe. O arranjo passa a interessar aos } \\
\text { bancos, que, por conhecer melhor o setor e } \\
\text { seus empresários, aumentam as operações } \\
\text { de crédito. O produto já começa a ser identi- } \\
\text { ficado com alguma característica sociocultu- } \\
\text { ral local. Realizam-se de forma mais constan- } \\
\text { te pesquisas relativas a inovações técnicas e } \\
\text { questões mercadológicas. }\end{array}$ & $\begin{array}{l}\text { Foco setorial; } \\
\text { Ainda tem estrangulamentos nos elos da } \\
\text { cadeia produtiva; Dificuldade no acesso } \\
\text { a serviços especializados (tecnologia/ } \\
\text { design/crédito); Interação com entidade } \\
\text { de classe; } \\
\text { Mercado local, estadual, nacional. }\end{array}$ \\
\hline $\begin{array}{l}\text { Arranjos Desenvolvidos } \\
\text { ( APILs) }\end{array}$ & $\begin{array}{l}\text { São aqueles arranjos produtivos cuja inter- } \\
\text { dependência, articulação e vínculos consis- } \\
\text { tentes resultam em interação, cooperação } \\
\text { e aprendizagem, possibilitando inovações } \\
\text { de produtos, processos e formatos organi- } \\
\text { zacionais e gerando maior competitividade } \\
\text { empresarial e capacitação social. }\end{array}$ & $\begin{array}{l}\text { Foco territorial; } \\
\text { Interação com a comunidade; } \\
\text { Mercado estadual, nacional, internacional; } \\
\text { Relacionamento comercial estreito entre } \\
\text { bancos e empresas; Base institucional } \\
\text { local diversificada e abrangente. }\end{array}$ \\
\hline
\end{tabular}

Fonte: Elaborado pelo autor, com base na pesquisa realizada, Castro, Luiz Humberto de. Arranjo produtivo local / Luiz Humberto de Castro. -- Brasília: SEBRAE, 2009. 44 p. (Série Empreendimentos Coletivos) 
Segundo os estágios do SEBRAE na formação dos APLs, entendemos que o caso dos polos moveleiros pernambucanos se encontram no primeiro estágio, ou seja, incipientes.

\subsection{Os Polos moveleiros pernambucanos}

Os polos produtivos de empresas são formados por grupos de firmas concentradas em um determinado espaço geográfico, trabalhando num setor específico, normalmente utilizando base tecnológica com similaridade. $O$ setor produtivo moveleiro é bastante representativo na formação de polos, quando as empresas formadas, mantém similaridades de processos, de produtos e linha de produção.

$\mathrm{Na}$ atuação nos polos estas empresas não estão necessariamente cooperadas ou associadas, mas na formação de clusters é imprescindível. Um cluster de pequenas empresas compreende-se como conjuntos de organização que trabalham cooperando entre si, cada uma das firmas executando um estágio do processo de produção.

O SEBRAE define um cluster como concentrações geográficas de empresas - similares, relacionadas ou complementares - que atuam na mesma cadeia produtiva auferindo vantagens de desempenho por meio da locação e, eventualmente, da especialização. Essas empresas partilham, além da infraestrutura, o mercado de trabalho especializado e confrontam-se com oportunidades e ameaças comuns.

A colaboração e aprendizado dentro do cluster geram elevados níveis de produtividade, formando aglomerados dentro dos quais os impactos das sinergias positivas entre os participantes é maior do que a soma dos esforços individuais de cada participante. A existência de um cluster deve ter alguns condicionantes, como por exemplo, existir uma aglomeração de empresas; compartilhamento de atividades por um número expressivo de firmas; um relacionamento de forma intensiva e contínua entre estas empresas. Ao redor das firmas integrantes do sistema de clusters existe, frequentemente, uma rede de instituições públicas e privadas.

A formação dos polos segue a regra básica de formação de qualquer polo industrial, quando pequenas empresas surgem a partir de uma empresa "mãe" normalmente estimuladas pelas concessões de benefícios fiscais da localidade, pela visão empreendedora de alguns e pela necessidade de negócios da cadeia produtiva mais próxima da localidade.

De acordo com o SINDMÓVEIS/PE, o estado de Pernambuco conta com vários polos regionais de fabricação de móveis, destacando-se os polos da Região Metropolitana do Recife, Gravatá, Afogados da Ingazeira e João Alfredo. Dentre estes, focaremos em dois polos frutos de um projeto de extensão em andamento.

\subsubsection{Polo de Gravatá}

Estima-se que existam na cidade de Gravatá entre 300 e 400 fábricas. A maioria funciona com estrutura familiar, gerando cerca de 2.000 empregos. São fabricados móveis para residências e escritórios, com uma fabricação voltada à utilização de madeira maciça nos estilos rústicos, semi-rústicos e country.

Uma das características deste polo moveleiro é oferecer exclusividade. A fabricação não é seriada, mas por encomenda e segue o desejo do cliente, com desenho mais personalizado. Em decorrência da importância para a cidade do setor moveleiro, a prefeitura urbanizou a Rua Duarte Coelho, onde se concentram as lojas de fábricas. No local, em cada uma das 60 lojas, os móveis dividem espaço com peças de decoração e do artesanato local.

A característica principal da produção dos móveis deste polo é a produção utilizando máquinas tradicionais de marcenaria, num processo produtivo classificado como semi- artesanal, de uso intensivo de mão de obra. A madeira é comprada em pranchas brutas, sendo a mais usual a angelim pedra, jatobá, embora algumas empresas já estejam usando prancha de lyptus (tipo de eucalipto) que não precisa passar pelo desengrossamento, haja vista que já vem aparelhada. Também já estão usando MDF, painéis de madeira de reflorestamento. O setor de artesanato e turismo é bastante intensivo

\subsubsection{Polo de Afogados as Ingazeiras}

Afogados das Ingazeiras, município que está localizado na região do sertão pernambucano e, como tantos outros, começa pela instalação de uma empresa principal, derivando outras concorrentes ou fornecedoras.

As duas principais empresas instaladas no município são a Magno Móveis e Móveis São Carlos, ambas com uma produção voltada para móveis de linha reta, tipo rack para TV, conjunto de sala, estantes. A produção destas empresas é seriada, contribuindo enormemente para o crescimento da economia local com o aparecimento de diversos fornecedores de implementos e matérias primas. Estas duas empresas são exemplos significativos de produção de móveis de linha reta. Estas empresas utilizam maquinário moderno e gerando vários empregos direto e indiretos para o município. Fora estas duas empresas, existem várias microempresas que recentemente formaram a APMAl- Associação dos Produtores de Móveis de Afogados as Ingazeiras.

A principal dificuldade do polo moveleiro de Afogados da Ingazeira, de acordo com a APMAI- Associação dos Produtores de Móveis de Afogados as Ingazeiras, é a falta 
de capacitação, visto que o ginásio industrial foi extinto desde os anos 70. As outras dificuldades citadas são a distância dos fornecedores de insumos, a falta de cultura empresarial na região.

O polo de Afogados da Ingazeira, apesar de distante dos fornecedores de insumos, é localizado em uma posição estratégica no que diz respeito à distribuição para as capitais da região nordeste. Afogados da Ingazeira está a menos de 400 quilômetros de três capitais nordestinas (Maceió, Recife e João Pessoa), a cerca de 550 quilômetros de Natal e Aracaju, a cerca de 650 quilômetros de Fortaleza e a menos de 900 quilômetros de Teresina.

Estes dois polos moveleiros pernambucanos constituem um território, com suas crenças, identidades culturais, valores sociais e econômicos, que estão sendo estudados no projeto de extensão em desenvolvimento, onde a sustentabilidade é fator primordial para sua existência e reconhecimento.

\subsection{ODesign e sustentabilidade para setor moveleiro}

Segundo (Pego, 2010, p:2, apud Santos ,2006, p:1) "A natureza de problemas ambientais é parcialmente atribuída à complexidade dos processos industriais utilizados pelo homem, fazendo uso dos diversos recursos tecnológicos".

Essa constatação trouxe o reconhecimento da necessidade de mudanças na forma de exploração e utilização dos recursos naturais, assim como nas formas de produção, resultando no atual conceito de desenvolvimento visto sob o paradigma da sustentabilidade.

Para (MORAES, 2010, pag, 14) ". Na atualidade, para países produtores e designers que atuam em cenários mutantes, fluidos e complexos, o desafio deixa de ser o âmbito tecnicista e linear, passando à arena ainda pouco conhecida e decodificada dos atributos intangíveis dos bens de produção industrial. Isso faz também com que o design interaja, deforma transversal, com disciplinas cada vez menos objetivas e exatas, passando a confluir com outras que compõem o comportamento humano e social, os fatores sensoriais e psicológicos".

Sustentabilidade é um conceito sistêmico, relacionado com a continuidade dos aspectos econômicos, sociais, culturais e ambientais da sociedade humana. Propõe-se a ser um meio de configurar a civilização e atividade humanas, de tal forma que a sociedade, os seus membros e as suas economias possam preencher as suas necessidades e expressar o seu maior potencial no presente, e ao mesmo tempo preservar a biodiversidade e os ecossistemas naturais, planejando e agindo de forma a atingir pró-eficiência na manutenção indefinida desses ideais.

O design baseado na sustentabilidade, deve repensar a forma como estão sendo produzidos, comercializados os produtos e serviços, como também o destino final o descarte.

Para projetar produtos e serviços, baseados na sustentabilidade, repensar a utilização dos materiais, sua origem, aplicar os 3 Rs, (Reduzir, Reusar, Reciclar). Pesquisar continuamente novos materiais, aperfeiçoar técnicas de fabricação, montagem, desmontagem e descarte. Projetar baseado na diminuição do uso da energia, no ciclo de vida dos produtos.

Projetar para setor moveleiro aplicando os conceitos de sustentabilidade, deve-se pensar a cadeia produtiva completa, desde a matéria prima, processos produtivos, comercialização, usabilidade do produto pelo consumidor e descarte. Diminuição dos componentes, facilidade de montagem e desmontagem, facilidade de transporte, multifuncionalidade, são algumas das metas no projeto de produto. Uma outra questão são os resíduos originário do processo produtivo, se recicla ou onde vai para o meio ambiente. Outro fator importante e comumente não observado, é a questão de segurança no trabalho, adequação do meio físico do setor produtivo ao trabalhador e sua saúde. Esta deveria ser mais uma dimensão a ser considerada no projeto do produto: saúde do trabalhador, ergonomia de produção.

O desenvolvimento sustentável, de uma maneira simplificada, procura satisfazer as necessidades da geração atual, sem comprometer a capacidade das gerações futuras de satisfazerem as suas próprias necessidades. Isto significa que as duas gerações atinjam um nível satisfatório de desenvolvimento econômico, social, cultural, fazendo, ao mesmo tempo, um uso razoável dos recursos do planeta, como também preservando as espécies e os habitats naturais.

Baseado nestes conceitos, a sustentabilidade dos polos moveleiros pernambucanos se dará efetivamente, quando os microempresários se derem conta da necessidade de formação de um APL, da compreensão de valorização do seu território, suas identidades e valores. Compreensão da cadeia de valor da localidade, mudança cultural na produção dos móveis preocupado com o meio ambiente e ciclo de vida dos produtos.

Como cadeia valor entende-se como um conjunto de atividades criadoras de valor, as origens das matérias primas básicas, passando por fornecedores de componentes e indo até o produto final entregue nas mãos do consumidor. Este conjunto de atividades de uma organização é um amplo sistema de relações com os fornecedores, ciclos de produção e de venda, até à fase da distribuição final.

Formado o APL, o design deve ser o suporte para o fortalecimento do mesmo, buscando sinergia entre os diversos atores participantes do Arranjo, tais como empresas, fornecedores, governos municipais e estaduais, SEBRAE, 
órgãos de financiamentos e fomento, universidades, centros de pesquisas tecnológicas, dentre outros. Baseado em (Krucken, 2009, p:51 e 52), o design deve atuar nas seguintes ações:

A. Identificar e explorar de forma sustentável o potencial dos recursos e competências situadas no território;

B. Projetar e desenvolver novos produtos e serviços diferenciados e com alto valor agregado, com base nos recursos, nas competências disponíveis e na riqueza cultural, identificados conforme item anterior;

C. Processos colaborativos de inovação e aperfeiçoamento do design local, promovendo o diálogo de tradição e inovação, fortalecendo o sentido de pertença da comunidade;

D. Desenvolver uma cultura de co-produção de valorese de processos produtivos colaborativos, entre os diversos atores;

E. Fortalecer a imagem do território, de seus produtos, serviços e empresas, dando maior visibilidade internamente e externamente;

F. Projetar novas interfaces e formas de intermediação entre os produtores/produtores, entre produtores/consumidores (redes e cadeias de valor), mas sempre envolvendo os recursos e potencialidades das empresas e do território;

G. Resgatar os valores e cultura local, desenvolvendo produtos a partir de matérias-primas alternativas disponíveis no território, além de utilização de subprodutos e resíduos.

Na nossa conclusão ressaltamos como os polos devem buscar a sua sustentabilidade, baseado na valorização do território.

\section{CONCLUSÃO}

Concluímos neste artigo que as pesquisas dos referenciais sobre a Valorização do Território, no Design e Inovação Sustentável, que foram as temáticas principais, são ferramentas fundamentais para que as empresas se diferenciem neste mercado globalizado e massificado. Estas empresas atuam numa produção desenfreada baseadas nos aspectos mais tangíveis do que subjetivos. Toda esta reflexão foi primordial para realizarmos um estudo de caso de dois polos moveleiros pernambucanos, fruto de um projeto de extensão que está em desenvolvimento. Neste projeto os passos seguintes são aplicar a metodologia e ações sugeridas, notadamente por Krucken (2006) e pelo Moraes (2010), num projeto semelhante aplicado em polos moveleiros de Ubá, Goiânia, Oeste de Santa Catarina.

Algumas ações já foram executadas neste projeto de extensão, que mostramos a seguir como resultados parciais obtidos:

Em Afogados da Ingazeiras realizamos um lay out para implantação das empresas nos seus boxes e produção seriada futura, na parte central e em cada box das empresas da APMAI (Fig.1) e redesign da marca da APMAl, como forma de fortalecer e comunicar a imagem do território (Fig.2).

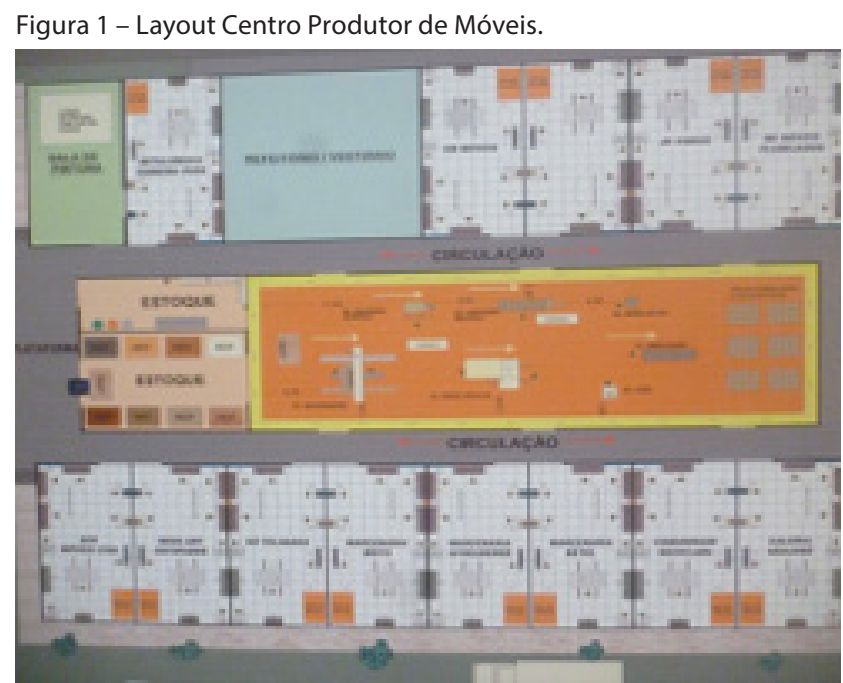

Fonte: Elaborado pelo autor, com base na pesquisa realizada.

Figura 2 - Marca antiga e ao lado a redesenhada, como forma de fortalecer

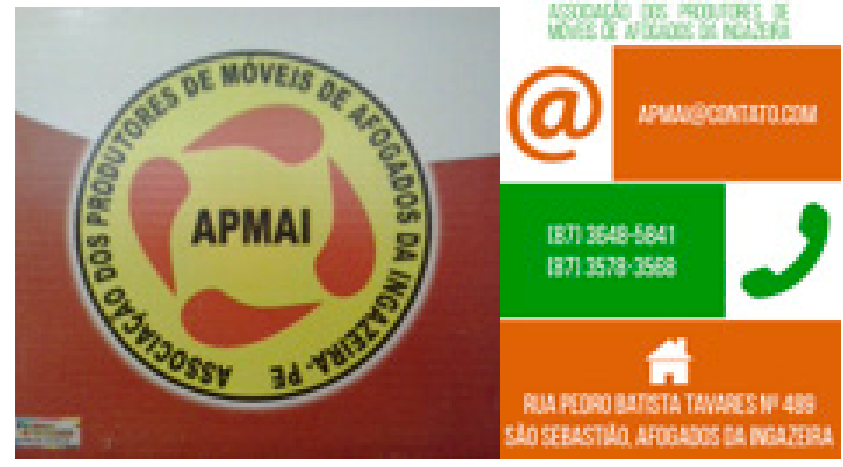

Fonte: Elaborado pelo autor, com base na pesquisa realizada do projeto de extensão.

No polo de Gravatá, começamos por uma Oficina de Design Sustentável, onde foram passados conceitos de sustentabilidade e no final criado produtos simplificados, de acordo com característica de cada empresa participante. Protótipo de Relicário, em madeira de demolição (pinho de Riga), executado pela empresa MARIART Móveis em Madeira de Demolição e Revisteiro todo por encaixes e meia madeira, que pode se transformar em mesa de centro, com conceito de mínimo de peças e forma de uma Gaivota com asas abertas. Protótipo em timburana encerada, pela empresa PARAGOMINAS (Fig. 3). 
Figura 3 - Protótipos criados na primeira Oficina de Design Sustentável, polo de Gravatá.

\section{REFERÊNCIAS}

Cadernos de Estudos Avançados: Identidade/organização: Morais, Dijon de; Krucken, Lia; Reyes, Paulo. Universidade do Estado de Minas Gerais - Barbacena: EdUEMG, 2010.

Castro, Luiz Humberto de. Arranjo produtivo local. Brasília:SEBRAE, 2009.44 p. (Série Empreendimentos Coletivos).

JOSÉ, Regina Gauer; JUNIOR, Giorgio Giorgi. Design e Sustentabilidade. Disponível em: http://www.usp.br/ fau/disciplinas. Acesso em 26 fev, 2011.

KRUCKEN. Lia. Design e Território: valorização de identidades e produtos locais. 1ª Ed. São Paulo: Studio Nobel. 2009.

KRUCKEN, Lia. Design e território: uma abordagem integrada para valorizar identidades e produtos. São Paulo: 20 Simpósio Brasileiro de Design Sustentável, 2009. Disponível na internet por http em: <http://portal.anhembi. br/sbds/anais/ISSD2009-P-06.pdf. Acesso em 29 ago. 2015.

LASTRES, Helena Ma Martins - Avaliação das Políticas de Promoção de Arranjos Produtivos Locais no Brasil e Proposição de Ações. Redesist, 2007.

LÖBACH, Bernd /Tradução Freddy Van Camp. Design Industrial: bases para a configuração dos produtos industriais. São Paulo: Edgar Blücher Ltda, 2001.

MANZINI, Ezio; VEZOLLI, Carlo. O desenvolvimento de produtos sustentáveis. Tradução de Astrid de Carvalho. $1^{\circ}$ ed. São Paulo: Ed USP, 2005.

Metodologia de desenvolvimento de arranjos produtivos locais. Projeto PROMOS/SEBRAE /BID. Disponível em: http://www.sebrae.com.br/br/cooperecrescer/projetopromos.asp. Acesso em: 04 julho, 2015.

PÊGO, K. A. C; Pereira, A. F; Carrasco, E. V. M. (2010). Método INPAR - Inserção de Parâmetros Ambientais no Design de Produtos. 9o Congresso Brasileiro de Pesquisa e Desenvolvimento em Design, 2011.

PORTER, Michael. Vantagem competitiva. São Paulo: Editora Campus, 1989.

SEBRAE/NA - Termo de Referência para Atuação do Sistema SEBRAE em Arranjos Produtivos Locais - junho de 2003. 